\title{
Karl Popper: Logik der Forschung. Zur Erkenntnistheorie der modernen Naturwissenschaft, vi +248 pp. Springer: Berlin
} 1935.

\section{Grete Hermann ${ }^{1}$}

Published online: 10 December 2020

(C) The Author(s) 2020

Popper wishes to set up the "rules of the game "empirical science"" (p. 22) ["rules of the game of empirical science", p. 32]. ${ }^{1}$ In fact, what he offers as the pattern of scientific research is nothing but a game with statements that, if anything, express only prejudices. The interest lies not in this outcome, but in the path that leads to it.

Indeed, Popper's constructions are based on two thoughts that are undoubtedly correct and significant for natural philosophy-largely leaning on positivist lines of reasoning, but in some places pursuing these uncommonly far to their extreme consequences. The first one: testing and justification of physical hypotheses never aims for an absolute and definitive foundation (verification); it rather exposes the stated claims to the possibility of being refuted (falsified) by contrary facts, abandons them in the case of such refutation, and otherwise retains them as corroborated, but always with the right to retract them or to make refining corrections (p. 6f) [p. 10].

This is combined with the second observation: there is no statement of experience, as simple and primitive a claim as it may be, that in this sense is not already application of a theory and thereby shares its character of being at most a well corroborated hypothesis. For even the simplest general concepts under which we subsume the objects around us include aspects of law-like behaviour (p. 52f) [p. 76]; therefore their application goes already beyond the mere findings of perception.

On the basis of these considerations Popper builds his edifice of definitions and methodological prescriptions: empirical science is defined as a system of statements to which only the requirement of testability through experience applies (falsifiability), not that of rigorous

\footnotetext{
1 Translator's note: Where Hermann gives page references or quotations from Logik der Forschung, I add in square brackets the corresponding page references or quotations from The Logic of Scientific Discovery (in the 2002 Routledge Classics edition).
}

Grete Hermann—deceased (1901-1984).

Written by Grete Hermann, translated by Guido Bacciagaluppi, from the reprint in Herrmann, K. (2019). Grete Henry-Hermann: Philosophie_Mathematik-Quantenmechanik. Dordrecht: Springer, pp. 269-271. Originally published in German in Physikalische Zeitschrift 36(13), 481-482 (1935). Thanks to the editors for a careful reading of the translation.

Grete Hermann

g.bacciagaluppi@uu.nl

1 Østrupgård, Denmark 
foundation (p. 12f) [p. 18]. The question of a criterion for the degree of this testability is discussed in detail.

Already this definition bears rich fruit for natural philosophy. Since the testing of general physical statements consists only in checking the occurrence of particular statementspredictions - drawn from them, for Popper all the difficulties disappear that are connected with the attempt to found general statements of experience: the problems of induction and of causality are eliminated.

But further: since also the singular statements of experience- - the basic statements that bring about failure or corroboration of theories - enter the investigations only as applications of theoretical posits, in the end failure or corroboration of theories is brought about by other theories that already count as corroborated. (In particular, a theory can be refuted by a singular statement only when this refutation takes place in the framework of a refuting theory that is itself corroborated by the singular statement, p. 47 [p. 66].) But now, where should the chain of theories end that corroborate or refute one another? Popper prescribes: there may be no limits to testability; but since testing must stop somewhere, and since the basic statements to which it stretches are as little capable of rigorous foundation as other statements of experience, it shall be left to the researcher to decide on their acceptance, in a way that can be explained by the experiences that have convinced them, but is unjustified and unjustifiable. These basic statements, which decide on the corroboration or failure of physical theories, are "from a logical point of view arbitrary stipulations" (p. 65) ["from the logical point of view, accepted by an act, by a free decision", p. 92]. ${ }^{2}$

Popper has again freed himself in one stroke from a whole knot of problems in natural philosophy-from all those that concern the cognitive character of perception and the possibility of founding empirical judgements in perception. At the same time it becomes clear what price he pays for this release from natural-philosophical difficulties: through definitions he has first curtailed the claim to truth of the empirical sciences, then completely thrown it out of the study of nature. The pains of justifying it are clearly gone, but only because science is debased to a blind play of dogmatic whimsy. The comfort offered by Popper, that "this kind of dogmatism' is 'harmless", because the basic statements accepted through arbitrary stipulation may indeed "be tested further if the need to do so should arise" (p. 61) ["this kind of dogmatism is innocuous since, should the need arise, these statements can easily be tested further", p. 87] is unable to cast a more favourable light on this outcome. Arbitrariness is not reduced by removing it step by step to ever different places.

The two crucial thoughts mentioned at the beginning, which are the starting point for Popper's considerations, hold true. They have always presented difficulties and problems for the interpretation of physical research in terms of natural philosophy. They must be confronted by those who ask of scientific claims the Kantian question 'Quid juris?'. Popper asks this question (p. 4) [p. 7]; but he forgets to account to himself or the reader what the claim to knowledge is in fact directed towards. Thus for him the question: Quid juris? shifts furtively to the other question: How should this claim to knowledge be constituted in order to blend as smoothly as possibly with the two mentioned characteristics of science? Understandably, the easiest solution is to eliminate such a claim to knowledge completely. But this observation has nothing to do with justifying physics' claim to knowledge.

Quite as to illustrate how Popper's considerations fall beside the point of the problems raised by physics, the only example treated in detail—the interpretation of Heisenberg's

\footnotetext{
${ }^{2}$ Translator's note: The original emphasis and wording in Popper is "logisch betrachtet, willkürliche Festsetzungen".
} 
uncertainty relations-is based on a misunderstanding of quantum mechanics. The physical mistake in the crucial thought experiment-which is supposed to show the possibility of predicting under appropriate conditions the position and momentum of an electron with a precision exceeding the uncertainty relations-has already been clarified in Popper's controversy with Weizsäcker (Naturwissenschaften 22, issue 48 of 30 November 1934). The more detailed treatment of quantum mechanics that Popper gives in his book reveals the reason for this mistake. Popper lets himself be misled by the probabilistic interpretation of the wave functions into applying these quantum mechanical state descriptions (and the uncertainty relations they lead to) only to ensembles of physical systems-according to the procedure in probability theory of translating statements about probabilities into statements about relative frequencies. He thus does not presuppose that an appropriately selected individual system must respect the uncertainty relations. In this he neglects that the duality experiments force one to apply features of the particle picture as well as of the wave picture already to individual systems, but thereby also to limit the applicability of the two pictures in accordance with the uncertainty relations. How these two sides of the quantum mechanical formalism - on the one hand the probabilistic interpretation of the wave function, on the other its utilisability as a state description of an individual physical system-are to be reconciled is a physical problem that is solved by Bohr's doctrine of complementarity, but cannot be eliminated through a one-sided limitation to the probabilistic approach.

Open Access This article is licensed under a Creative Commons Attribution 4.0 International License, which permits use, sharing, adaptation, distribution and reproduction in any medium or format, as long as you give appropriate credit to the original author(s) and the source, provide a link to the Creative Commons licence, and indicate if changes were made. The images or other third party material in this article are included in the article's Creative Commons licence, unless indicated otherwise in a credit line to the material. If material is not included in the article's Creative Commons licence and your intended use is not permitted by statutory regulation or exceeds the permitted use, you will need to obtain permission directly from the copyright holder. To view a copy of this licence, visit http://creativecommons.org/licenses/by/4.0/.

Publisher's Note Springer Nature remains neutral with regard to jurisdictional claims in published maps and institutional affiliations. 